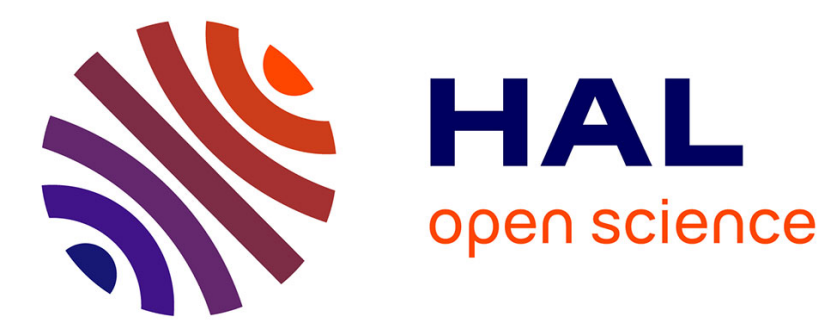

\title{
Electrospun fibers in regenerative tissue engineering and drug delivery
}

\author{
Sakthivel Nagarajan, Céline Pochat-Bohatier, Sébastien Balme, Philippe \\ Miele, S. Narayana Kalkura, Mikhael Bechelany
}

\section{- To cite this version:}

Sakthivel Nagarajan, Céline Pochat-Bohatier, Sébastien Balme, Philippe Miele, S. Narayana Kalkura, et al.. Electrospun fibers in regenerative tissue engineering and drug delivery. Pure and Applied Chemistry, 2017, 89 (12), pp.1799-1808. 10.1515/pac-2017-0511 . hal-01675232

\section{HAL Id: hal-01675232 \\ https://hal.umontpellier.fr/hal-01675232}

Submitted on 15 Jun 2021

HAL is a multi-disciplinary open access archive for the deposit and dissemination of scientific research documents, whether they are published or not. The documents may come from teaching and research institutions in France or abroad, or from public or private research centers.
L'archive ouverte pluridisciplinaire HAL, est destinée au dépôt et à la diffusion de documents scientifiques de niveau recherche, publiés ou non, émanant des établissements d'enseignement et de recherche français ou étrangers, des laboratoires publics ou privés. 


\title{
Electrospun fibres in regenerative tissue engineering and drug delivery
}

\author{
Sakthivel Nagarajan ${ }^{1,2}$, Céline Pochat-Bohatier ${ }^{l}$, Sébastien Balme, ${ }^{1}$ Philippe Miele ${ }^{1}, \quad S$ \\ Narayana Kalkura, ${ }^{2 *}$ and Mikhael Bechelany ${ }^{1 *}$ \\ ${ }^{1}$ Institut Européen des Membranes, UMR 5635, Université Montpellier, CNRS, ENSCM, \\ Place Eugene Bataillon, F-34095 Montpellier cedex 5, France \\ ${ }^{2}$ Crystal Growth Centre, Anna University, Chennai, India, 600025. \\ * Corresponding authors: kalkura@yahoo.com and mikhael.bechelany@umontpellier.fr, \\ Phone: +33467149167, Fax: +33467149119
}

\begin{abstract}
Electrospinning is a versatile technique to produce micron or nano sized fibers using synthetic or bio polymers. The unique structural characteristic of the electrospun mats (ESM) which mimics extracellular matrix (ECM) found influential in regenerative tissue engineering application. ESM with different morphologies or ESM functionalizing with specific growth factors creates a favourable microenvironment for the stem cell attachment, proliferation and differentiation. Fiber size, alignment and mechanical properties affect also the cell adhesion and gene expression. Hence, the effect of ESM physical properties on stem cell differentiation for neural, bone, cartilage, ocular and heart tissue regeneration will be reviewed and summarized. Electrospun fibers having high surface area to volume ratio present several advantages for drug/biomolecule delivery. Indeed, controlling the release of drugs/Biomolecules is essential for sustained delivery application. Various possibilities to control the release of hydrophilic or hydrophobic drug from the ESM and different electrospinning methods such as emulsion electrospinning and coaxial electrospinning for drug/biomolecule loading are summarized in this review.
\end{abstract}

\section{Introduction}

Tissue engineering is an interdisciplinary field. It focused on the improvement of the biological function of tissues and organs using cells, materials and biochemical factors. Current treatments for the failure of tissues and organs are limited due to the shortage of donors and immune response problems. These challenges can be overcome through regenerative medicine. This approach allows regenerating the damaged or malfunctioned tissues and organs using the self-healing capacity of the body. The scaffolds which mimic extra cellular matrix (ECM) are essential in regenerative medicine. It provides structural support and suitable microenvironment by releasing growth factors to cells for differentiation. Various techniques for the culture of 3D tissue such as cell sheet technology, polymer based technology and cell spheroid are most commonly employed in regenerative medicine [1]. However, polymer based scaffolds are most suitable in regenerative medicines and successfully practised for the regeneration of tissues [2, 3].

The nanofibrous polymer based scaffolds are advantageous due to the high surface area to volume ratio, porous structures, ability to mimic ECM like structure and suturability and could be easily fabricated into different shapes [4]. Various methods are available to produce the nanofibers such as self-assembly, phase separation and electrospinning, etc. Among these methods, electrospinning is a versatile technique for mass production and continuous nanofibers assembly generation [5]. The unique structural characteristic of these nanofibers found application in energy, environmental and health [6-12]. 
The delivery of drugs and biomolecules to the therapeutic site in a controlled fashion for tunable period is requisite to induce tissue healing and cell differentiation. The drugs and biomolecules can be immobilized using various electrospinning process (co-axial, side-byside electrospinning and triple coaxial electrospinning) and can be controlled for tunable release. Drugs and biomolecules such as antibiotics, anticancer, proteins, growth factors, and nucleic acid loaded polymer based electrospun fibers are widely studied and compiled in this report to understand their release behavior.

This report aims to review various polymer based electrospun nanofibrous constructs for the differentiation of stem cells to regenerate bone, cartilage, nerve, liver, retinal, corneal, skin and heart tissue. The influence of fiber diameter and fiber alignment will be also investigated. Importance of electrospun fibers in biomolecule and drug delivery will be also briefly reviewed.

\section{Regenerative tissue engineering}

The regenerative tissue engineering aims to restore the normal function of organs, tissues and cells using scaffolds and growth factors. Designing material with suitable physical and chemical properties is essential in regenerative medicine. The scaffolds used for regenerative tissue engineering are prepared using biopolymers (collagen, chitosan, etc.) and synthetic polymers. Biopolymers are highly degradable and display biocompatibility. However, synthetic polymers also exhibit their own advantages such as high mechanical properties and biocompatibility. Hence, selecting suitable polymer candidate for scaffold fabrication is indispensable. Researchers are paying their attention towards the electrospun based nanofibers for regenerative medicine [13]. Understanding the various literatures on polymer based fibrous scaffolds and the influence of surface topography, alignment of fibers, diameter of fibers and texture of fibers on stem cell differentiation is briefly reviewed in this manuscript in order to understand the current status of electrospun fibers on various regenerative medicines. It is essential to design the next generation of scaffolds.

\section{Nerve regenerative tissue engineering}

The nerve is a pathway which transmits electrochemical nerve impulses to periphery of organs along the nerve fiber (axon). The bundles of nerve fibers are enclosed in irregular connective tissues known as epineurium. Each bundle is surrounded by perineurium and the endoneurium covers each nerve fiber. Damage of any layer of nerve is knows as nerve injury which leads to a gap between proximal and distal stump. The grafts play an important role to direct cells in order to fix the gap [14]. The autograft is limited due to insufficient donor tissue, pain at the donor site and size mismatching of donor nerve $[14,15]$. The polymer based grafts are advantageous due to their biocompatibility, biodegradability and suitable mechanical properties. Stem cells cultured on polymer ESM are induced to regenerate the nerve injury. Neural crest stem cells (NCSC) derived from induced pluripotent stem cells (iPSC) are seeded on electrospun nerve conduit and induces the sciatic nerve regeneration in one month [16]. Human adipose-derived stem cells were differentiated into Schwann like cells using PLGA/chitosan ESM. Retinal ganglion cells possess low regeneration capacity and iPSC differentiated into retinal ganglion cells using PLGA ESM [17]. These results show that the synthetic/ bio polymers are suitable for stem cell (SC) attachment. SC attachment and differentiation is tunable based on the nanoscale structures of the ESM, immobilizing suitable instructive cues on the fibers. Immobilizing such bioactive molecules provides favourable microenvironment to the stem cells and ameliorates their differentiation. poly-L-lactic acid/gelatin ESM with suitable instructive cues promotes the differentiation of neural stem cells into motor neurons [18]. Functionalizing with collagen improves the stem cell attachment and viability [19]. Encapsulating neural growth factors (NGF), glial cell derived 
neutrophic factor in nanofibers, facilitates the guided nerve regeneration. Surface properties such as roughness and hydrophilicity improve the cell attachment and differentiation. Functionalizing aligned PLLA ESM with graphene oxide improves hydrophilicity in comparison to PLLA and amine grafted PLLA which supports the PC12 cell differentiation with long neurites [20]. Electrospun fiber alignment influences stem cell attachment and proliferation. Zuidema et al. found that aligned PLLA fibers exhibits longest neurites in comparison to PLLA films [21]. High effective stiffness of the aligned fibers helps the cells to push or pull along the matrix for migration. It also facilitates the proliferation, whereas buckling of random fibers limits the migration and adhesion. Aligned nanofibers enhances the embryonic stem cells (ESCs) differentiation and controls the neurite direction, oligodendrocyte migration along the aligned fiber direction in comparison to random fibers as shown in Figure 1(c-h)[22]. Aligned fibers show robust neurite guidance that improves neurite outgrowth and axonal regeneration. Peptides functionalized nanofibers improve the differentiation of ESCs and upregulated neural gene expression grown. The ESC cultures on aligned electrospun fibers exhibit upregulated gene expression in comparison to random fibers $[23,24]$. Nerve graft can regenerate $10 \mathrm{~mm}$ defect in rat sciatic nerve whereas, recent studies prove that aligned ESM can regenerate $15 \mathrm{~mm}$ nerve defects [25].

Mechanical properties such as stiffness of the fibers decide the fate of stem cell differentiation. Progenitor cells cultured on soft PCL (7.1 MPa) expresses chondrogenic markers whereas at stiff fibers (30.6 MPa) expresses osteogenic markers [26]. Fiber diameter influences the cell differentiation, adhesion and migration. It evidenced that topographical cues plays important role [27]. In vivo studies proved that PCL ESM stimulates superior regeneration of sciatic nerve which has the G-ratio comparable to healthy nerve [28]. Collagen incorporation into PCL based ESM facilitates the differentiation of mesenchymal stem cells (MSCs) by improving expression of neurofilament protein and nestin. These studies evidence that modified electrospun provides suitable microenvironment to stem cells which facilitates their attachment, proliferation and differentiation into neural lineages. Hence ESMs are potential candidates in neural tissue regeneration application.
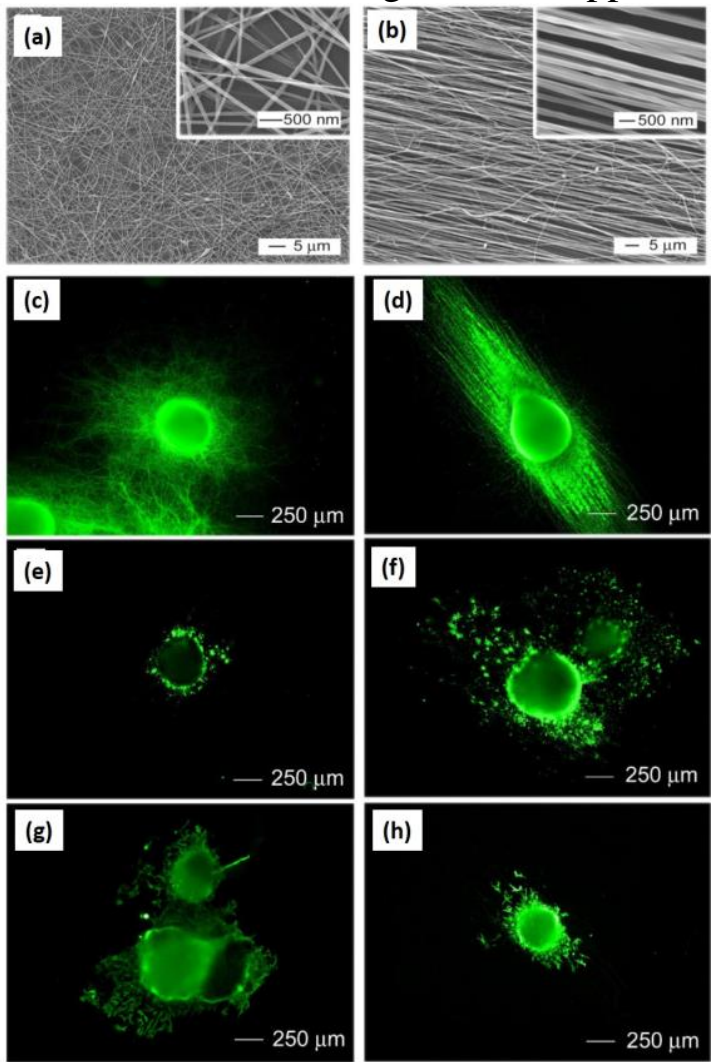
Figure 1. SEM micrograph of (a) Random fibers, (b) aligned fibers, immunostaining images of neural markers (c and d) Tuj1 on random and aligned fibers respectively, (e,f) O4 on random and aligned fibers respectively and $(\mathrm{g}, \mathrm{h})$ glia fibrillary acidic protein (GFAP) on random and aligned fibers respectively [22].

\section{Bone and cartilage tissue engineering}

Bones are the composite which mainly consists of hierarchically aligned collagen and hydroxyapatite. Collagen, glycoproteins and proteoglycans are the major organic content of bone. Regenerative bone tissue engineering is an important field of research aims to regenerate the damaged bone tissues using polymer based scaffolds. Polymer electrospun fibers and polymer fibers reinforced with inorganic material such as hydroxyapatite (HAp) and bioglass are widely used for the regeneration of bones and cartilages. HAp incorporated polymer fibers improve the bone marrow derived mesenchymal stem cells (BMSC) adhesion proliferation and differentiation. BMSC cultured on HAP/chitosan ESM and implanted in rat possesses improved bone regeneration in comparison to pure polymer fibers [29]. Incorporation of HAp and bone morphogenic protein in silk electrospun scaffolds improve osteogenic differentiation of human mesenchymal stem cells (hMSC) [30]. It shows that designing electrospun fibers reinforced with bone mineral HAp provides favourable environment for stem cell differentiation into osteoblast lineage. The nature and the molecular architecture of polymers in fibers are also important factor which control the stem cell differentiation. Chen et al. analyzed the differentiation of hMSC on ESM and found that molecular architecture of the polymer influences the stem cell differentiation [31]. The incorporation of PLA into Polycaprolactone (PCL) during the fiber fabrication improves the hMSC differentiation and invivo bone formation [32].

High voltage during the electrospinning affects the integrity, bioactivity of drugs and biomolecules. Liu et al. prepared fibroblast growth factor (FGF) loaded nanoparticles using dextran and fabricated an ESM with PLLA which maintains the integrity during electrospining [33]. However, PLLA ESM loaded with FGF nanoparticles induced in vivo tendon healing in rat model. It possesses also sustained release of growth factors, which evidenced that bioactivity of growth factors is maintained even after the electrospinning process. Loading suitable growth factors or creating microenvironment to the stem cells improves their differentiation. Functionalizing PLGA fibers with bone forming peptides enhanced the hMSC differentiation and induced the bone formation in mouse calvarium defects [34]. ESM with higher RGD densities improves the focal adhesion, cell spreading and proliferation of hMSC and improves the differentiation.

In spite that growth factors accelerate the stem cell differentiation, controlling the release of growth factor is crucial. Core shell electrospun fibers loaded with growth factors show sustained release and facilitate chondrogenic differentiation of BMSC [35]. Differentiation of stem cell could be tuned by applying dynamic mechanical stimulation on the construct. Dynamic mechanical stimulation induces tenogenic differentiation of tendon derived stem cells in vitro cultured on electrospun fibers [36]. Designing electrospun fiber scaffolds mimicking the physical properties of bone facilitates cell adhesion, proliferation and vascularization. Deng et al. prepared 3D ESM by rolling electrospun fibers by concentric manner in which ECM deposition was observed throughout the scaffolds [37]. ESM fabricated using poly(D,L-lactide-co-glycolide) (PLGA) polymer improved the differentiation of hMSC cells into osteoblast and chondrocytes [38]. PCL scaffolds seeded with hMSC cells ameliorated the cell infiltration and formation of ECM throughout the electrospun fibers [39]. Hence, ESM fabricated using synthetic and biopolymers are suitable scaffold constructs for the differentiation of stem cells in bone regenerative tissue engineering. 


\section{Ocular tissue engineering}

Eye is an important organ with complex optical system. Cornea, lens, retina, optical nerve etc. are the important components of eye. Damage or malfunctioning of these components is replaceable from the donors. Recent studies prove that organ scarcity from the donors can be solved using regenerative tissue engineering. Cornea is avascular and transparent. Damage of cornea due to bacteria, viral infection, trauma and ulceration can be regenerated using ESM scaffolds. Human amniotic membrane (HAM) is widely used as a wound dressing material for the reconstruction of damaged cornes. Juan et al. proved that chitosan modified collagen electrospun fibers are suitable wound dressing material for ocular surface injury and possess superior biological properties compared to HAM [40]. Electrospun membranes are suitable alternate for human amniotic membranes and to treat limbal stem cell deficiency which causes serious blinding diseases. Human limbal stem cells (hLSC) cultured on ESM revealed no significant change in the gene expression in comparison to cells cultured on human amniotic membrane. However, hLSC cells infiltration, attachment and proliferation were significantly high in the ESM. Current strategy to treat ocular surface damage is recruiting laboratory cultured limbal epithelial cells (LECs) on donor human amniotic membrane to the cornea. Deshpande et al. reported that LECs cultured from the electrospun fibers were successfully transferred to rabbit eye model which showed differentiated stem cell population. Hence, electrospun fibers combined with limbal explants are efficient material to replace human amniotic membrane [41].

Electrospun fibers are employed as a cell carrier for transferring the MSCs and LSCs cultured on ESM to treat stem cell deficiency and ocular surface injury [42]. Jitka et al. reported that alkali induced oxidative stress on the rabbit cornea was effectively treated using the stem cells cultured on ESM [43]. Cornea is avascular and maintaining the avascularity is crucial for transparency. MSCs cultured on electrospun fibers controls the vascularization in vivo and improves the corneal healing [43] as shown in the Figure 2. Designing electrospun fibers loaded with drug and cells are crucial in ocular tissue engineering. Electrospun fibers loaded with matrix metalloproteinase-2 (MMP2) and progenitor cells are used for corneal regeneration. However, release of MMP2 in controllable fashion from the ESM is advantageous to remove the inhibitory extracellular matrix protein which is heavily deposited at the dystrophic retina [44]. The literature revealed that polymer based electrospun fibers are potential material in ocular tissue engineering. 


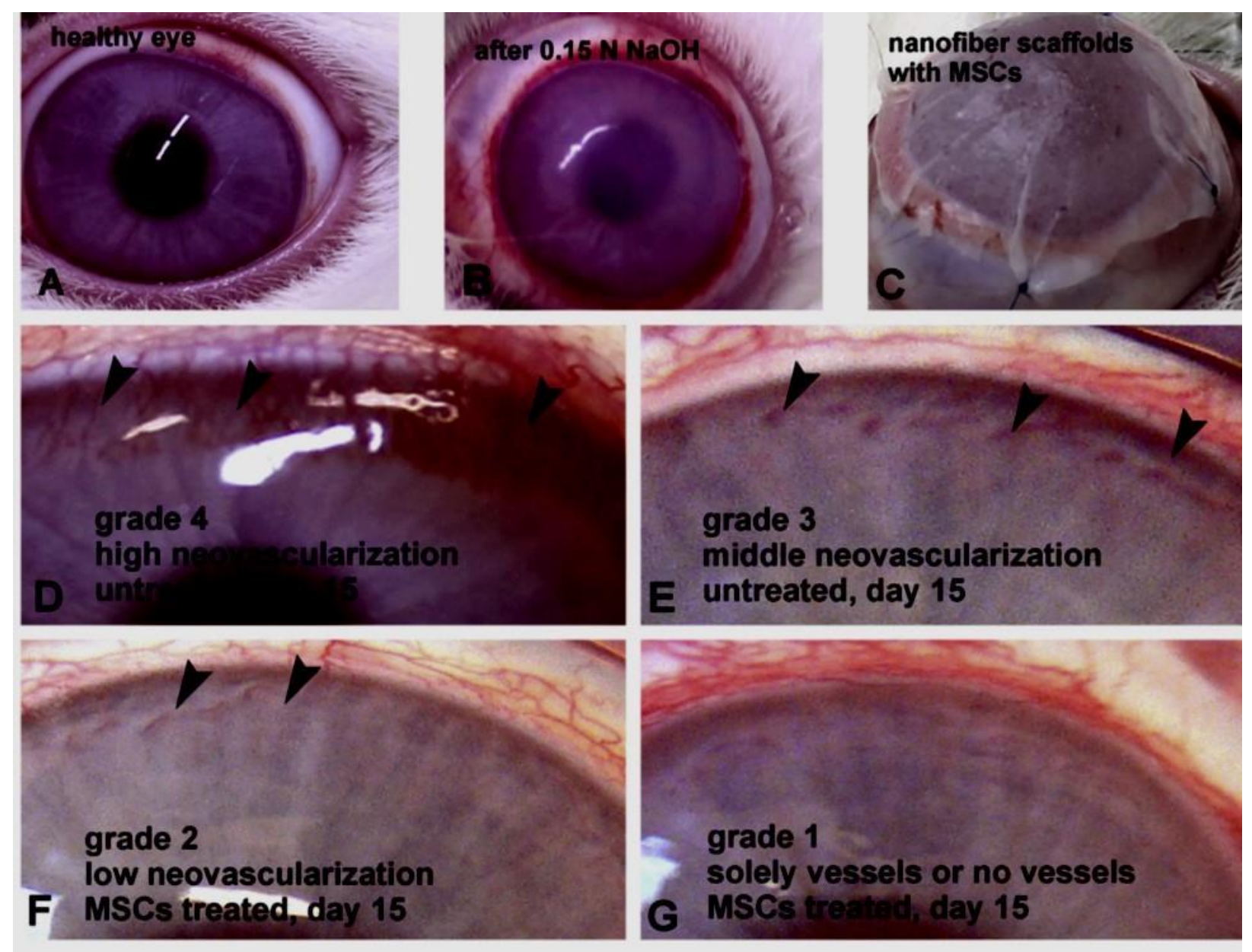

Figure 2. Photographs of alkali-injured corneas (with $0.15 \mathrm{~N} \mathrm{NaOH}$ ) and corneal neovascularization on day 15 after the injury. A-healthy rabbit eye, B-Immediately after the injury, Cnanofibers with MSCs sutured on injured cornea (nano fibers without MSCs also sutured on cornea). D- high neovascularization of alkali injured cornea untreated with MSCs). E- middle neovascularization of alkali injured cornea untreated with MSCs, F- low neovascularization of cornea injured with alkali and treated with MSCs. G- no or very low neovascularization of an alkali-injured cornea treated with MSCs [43].

\section{Cardiac tissue engineering}

Cardiac tissue engineering mainly focuses to repair or to regenerate the damaged blood vessel, valve and cardiac tissues. Damaged heart muscles cannot replace the injured site by its own heart muscle cell and cardiomyocites, due to their limited proliferative nature. The injury is treated by recruiting cells or replacing the injury with functioning cardiac tissue [45]. However, poor cell integration, loss of the cells and high cell death limits their success rate [46]. Polymer based scaffolds provides a favourable environment for the proliferation of the cells at injured site. Designing polymer scaffolds exhibits the mechanical properties similar to cardiac tissues are essential. Stimuli such as mechanical force from the cell contraction or external forces, electrical stimuli and chemical stimuli matrix stiffness, highly influence the cell differentiation [47]. Electrical conductivity of the scaffolds are essential to conduct the signals and it also improves the expression of cardiac related markers [48]. Electrospun fibers loaded with mesenchymal stem cells and electrically conductive gold nanoparticle improves the differentiation of MSC [49]. Mimicking fibrillary extra cellular matrix like structure is essential for survival, proliferation and differentiation of stem cells. Topography of the electrospun fibers influences the stem cell differentiation. iPSC cells cultured on PCL 
electrospun fibers exhibits enhanced cardiomyocyte differentiation in comparison to iPSC cultured on tissue culture plate [50]. Pierre et al. demonstrated that ESMs that exhibit similar mechanical properties of cardiac tissue and seeded with hiPSC derived cardiomyocite are suitable for cardiac tissue regeneration [51]. Human cardiac stem cell cultured on aligned electrospun fibers expresses the cardiac gene markers [52]. Mechanical properties of the electrospun fibers and strain experienced during the culture affects the stem cell differentiation. Injection of mesenchymal stem cells on the cardiac injury limits the cell alignment and induces poor differentiation, due to inherent strain of heart beat. However, Jianjun et al. reported that increasing the stretching strain of the fiber enhanced the MSC differentiation into cardiomyocites and enhanced the cell alignment which is suitable for cardiac regeneration [53].

Acute myocardial infarction limited the myocardial regeneration capacity and leads to the congestive heart failure. Hence designing suitable treatment methods is necessary. Vascular endothelial growth factor (VEGF), cardiac stem cells (CSC) loaded PLLA electrospun scaffolds enhanced the migration and proliferation of CSCs in-vitro. However, epicardially implanted VEGF and CSCs loaded electrospun scaffolds in-vivo results in the enhancement of angiogenesis and cardiomyogenesis in acute myocardial infarction [54]. PCL based electrospun scaffolds immobilized with fibronectin are an effective carrier for umblical cord blood derived stem cells to treat myocardial infarction [55]. Cardiac patches prepared using electrospun fibers with MSC exhibits also improved angiogenesis and enhanced cell migration from the scaffold to scar tissue [56]. PCL electrospun fibers loaded with elastin, collagen and ${\mathrm{c}-\mathrm{kit}^{+}}^{+}$cells decrease the myocardial infarction area of mice in comparison to PCL ESM as shown in the Figure 3 (Infarcted myocardium is stained white and healthy myocardium is stained red) [57]. Porous electrospun based PLLA scaffolds loaded with cardiovascular progenitor cells supports the large number of living cardiomyocites which are an important criteria to treat the scar tissue [58]. Hence, electrospun fibers loaded with stem cells are suitable alternate to the cellular cardiomyoplasty which can effectively treat the myocardial infarction.
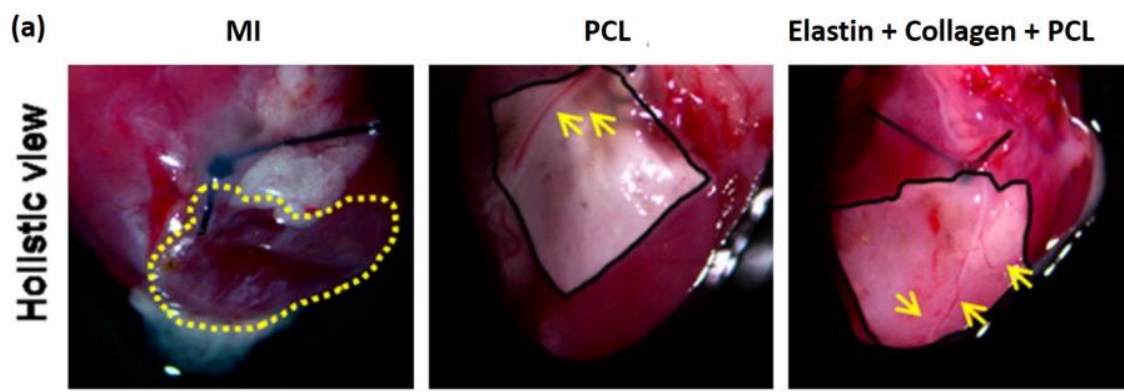

Elastin + Collagen + PCL + c-kit ${ }^{+}$

(b)
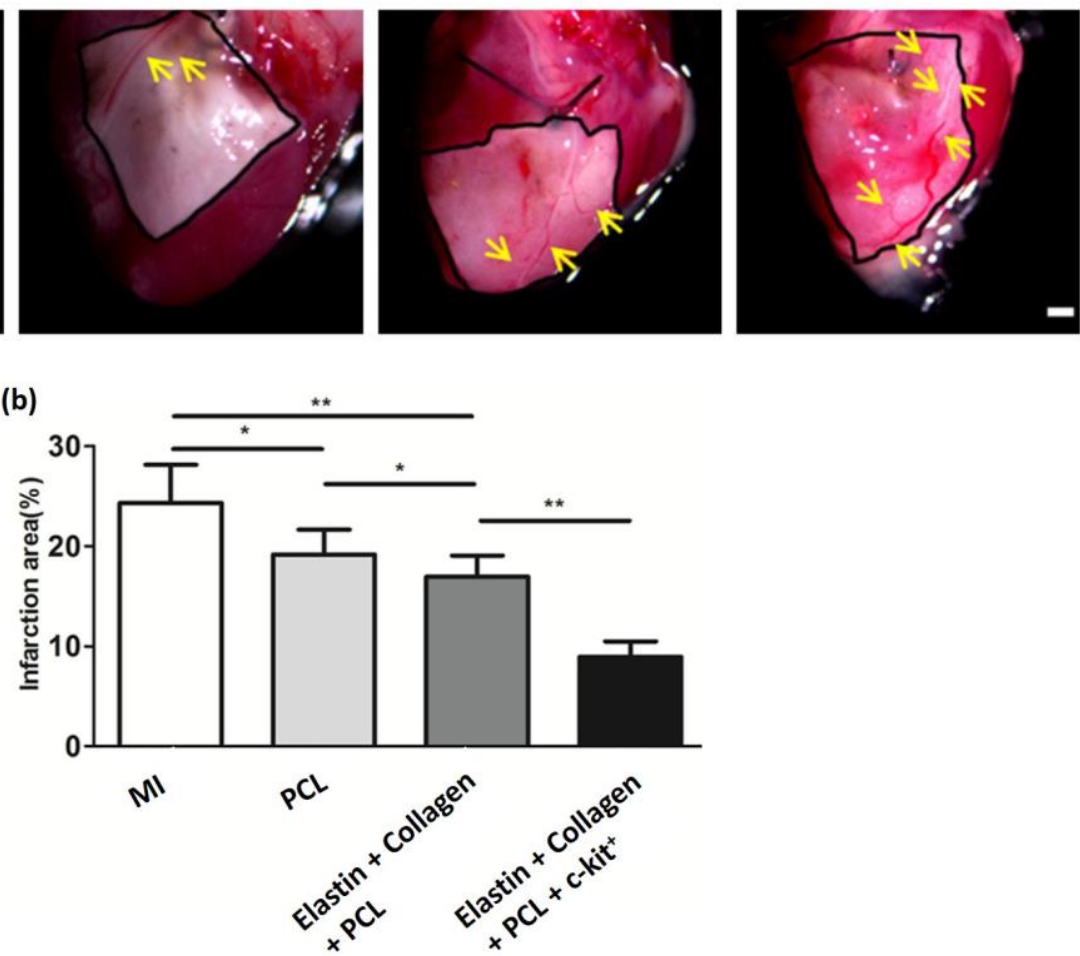
Figure 3. Holistic view and infarct size measurements. Mice hearts were collected at 28 days after transplantation: a) All the ESMs were covered the epicardium of left ventricles when hearts were collected. Ventricle aneurysms area in MI model is indicated using Yellow short dash line. Branches of new blood vessels are pointed using yellow arrows. Scale bar = $1000 \mu \mathrm{m}$ and (b) Statistical analysis of infarcted area ratio in whole tissue. $* \mathrm{P}<0.01$.

\section{Drug and biomolecule delivery}

Electrospun fibrous mats are highly advantageous for the delivery of drugs and biomolecules due to their high surface area and porosity. Various drugs such as anticancer, antibiotics biomolecules like growth factors, proteins, DNA and RNA loaded ESM are widely studied for delivery application. Size and alignment of electrospun fiber affects the drug release. Xie et al. proved that nanometer sized electrospun fibers show fast release of drugs in comparison to micron sized fibers. Highly aligned nanofibers show high fibers packing density and less pores which decreased the drug diffusion to surrounding, whereas random fibers possess porous structure and supports the drug release. PLGA/Chitosan aligned nanofibers loaded with fenfuben show poor drug release in comparison to random fibers [59]. Hence, designing electrospun fibers with suitable size and alignment is essential.

Release of hydrophobic drugs are mainly depends on the nature of polymer matrix. Electrospun fibers fabricated using hydrophobic PCL polymer exhibits poor drug release in comparison to PCL/Gelatin ESM. It is mainly due to the release of hydrophilic gelatin which facilitates the drug release [60]. Hydrophilic gelatin electrospun fibers loaded with Vitamin A and $\mathrm{E}$ display sustained release which is suitable for long time antibacterial nature and to improve the wound healing [61]. Biocompatible nanoparticles like hydroxyapatite are employed to immobilize antibiotic drugs such as amoxicillin and used to fabricate electrospun membranes which control the burst release of drugs through controlled diffusion [62]. Electrospun fibers with core/sheath structure are highly advantageous which helps i) to control the stability of degradable drugs by immobilizing in the core of the fiber, ii) to load drugs of different properties for biphasic drug release, and iii) to tune the drug release properties by varying the polymer sheath thickness.

Emulsion coaxial electrospinning controls the release of vascular endothelial growth factors [63]. Controlling the core of coaxial electrospun fibers is essential to achieve sustained drug delivery. Zhang et al. prepared ESM using fibroblast growth factors loaded hydrogel or emulsion as a core and found controlled release of growth factors [64]. Drug release from the polymer films can be controlled by covering the polymer surface using hydrophobic electrospun membranes. Xu et al. controlled 5-Fluoro uracil drug release from the polyvinyl butyral (PVB) films by hydrophobic modification using PVB electrospun fibers [65]. Degree of crosslinking of polymers and swelling ratio are the major factors which controls the drug release from the ESM. Nagarajan et al. proved that gelatin ESM loaded with drug revealed controlled release depends on the crosslinking density of gelatin polymer. A high concentration of crosslinker improves the crosslinking density which decreases the swelling of polymer films and results in poor drug release profile [66].

Controlled degradation of polymer ESM using enzymes or $\mathrm{pH}$ is a promising method for sustained drug release. Polymers like collagen, gelatine and chitosan are degradable by collagenase, gelatinase and lysozyme respectively which is favourable for the release of drugs from the polymer ESM. Emulsion electrospinning is a versatile tool to control the drug release by adjusting the emulsifier, water and oil ratio [67]. Qi et al. proved that fabricating emulsion electrospun fibers loaded with BSA microcapsules controls its release for long term in comparison to BSA microspheres [68]. Various researches revealed that electrospinning is a versatile tool for drug/biomolecule delivery application. Employing suitable electrospinning technique, polymer system is crucial to control the drug delivery. 


\section{Conclusions and future prospective}

Electrospun fibers fabricated using biodegradable biopolymer or synthetic polymers are suitable for regenerative tissue engineering. Various stem cell types cultured on ESM or surface modified ESM expressed markers specific to bone, neural and heart cells. Regeneration of infarcted heart tissue using stem cell/ESM patches, directing neurite extension using aligned fibers and regeneration of damaged cornea demonstrate the importance of electrospun fibers in regenerative tissue engineering. Electrospinning has been also used for controlled release of drugs/biomolecules by tuning the degree of crosslinking and the swelling ratio of the polymer. Degradation of drug loaded polymers using enzyme and $\mathrm{pH}$ also release drugs and biomolecules. Hence, electrospun fibers are promising constructs for regenerative tissue engineering and potential carrier for drug/biomolecules. Understanding and improving the clinical performance data of these electrospun membranes are essential. Designing suitable methods to fabricate highly thick and interconnected porous electrospun membranes will be advantageous in tissue engineering. Hence, overcoming the current hurdles is essential to fabricate a clinically functional material.

ACKNOWLEDGEMENTS: We acknowledge the financial support from Indo-French Centre for the promotion of advanced research-Cefipra (Project 5608-1), the Ligue Contre Le Cancer and the CNRS (Project "Osez l'Interdisciplinarité"). The authors would like to acknowledge the "Institut Européen des Membranes (IEM)-UMR 5635" which supports this study through the health project PS1-2015-NewBone.

\section{References}

1. T. Okano, N. Yamada, H. Sakai, Y. Sakurai. Journal of Biomedical Materials Research 27, 1243-1251 (1993).

2. $\quad$ K. Harding, M. Sumner, M. Cardinal. International Wound Journal 10, 132-137 (2013).

3. A. S. Mao, D. J. Mooney. Proceedings of the National Academy of Sciences 112, 14452-

14459 (2015).

4. $\quad$ A. Haider, S. Haider, I.-K. Kang. Arabian Journal of Chemistry.

5. Z.-M. Huang, Y. Z. Zhang, M. Kotaki, S. Ramakrishna. Composites Science and Technology

63, 2223-2253 (2003).

6. Z. Dong, S. J. Kennedy, Y. Wu. Journal of Power Sources 196, 4886-4904 (2011).

7. R. Sridhar, R. Lakshminarayanan, K. Madhaiyan, V. Amutha Barathi, K. H. C. Lim, S. Ramakrishna. Chemical Society Reviews 44, 790-814 (2015).

8. D. Selloum, A. A. Chaaya, M. Bechelany, V. Rouessac, P. Miele, S. Tingry. Journal of Materials Chemistry A 2, 2794-2800 (2014).

9. R. Viter, I. Iatsunskyi, V. Fedorenko, S. Tumenas, Z. Balevicius, A. Ramanavicius, S. Balme,

M. Kempiński, G. Nowaczyk, S. Jurga, M. Bechelany. The Journal of Physical Chemistry C 120, 5124-5132 (2016).

10. M. Bechelany, M. Drobek, C. Vallicari, A. Abou Chaaya, A. Julbe, P. Miele. Nanoscale 7, 5794- $5802(2015)$.

11. M. Nasr, S. Balme, C. Eid, R. Habchi, P. Miele, M. Bechelany. The Journal of Physical Chemistry C 121, 261-269 (2017).

12. S. Nagarajan, C. Pochat-Bohatier, C. Teyssier, S. Balme, P. Miele, N. Kalkura, V. Cavailles, M. Bechelany. RSC Advances 6, 109150-109156 (2016).

13. S. Peng, G. Jin, L. Li, K. Li, M. Srinivasan, S. Ramakrishna, J. Chen. Chemical Society Reviews $\quad$ 45, 1225-1241 (2016).

14. P. J. Johnson, M. D. Wood, A. M. Moore, S. E. Mackinnon. European surgery : ACA : Acta chirurgica Austriaca 45, 10.1007/s10353-10013-10205-10350 (2013).

15. G. R. D. Evans. The Anatomical Record 263, 396-404 (2001). 
16. A. Wang, Z. Tang, I.-H. Park, Y. Zhu, S. Patel, G. Q. Daley, S. Li. Biomaterials 32, 50235032 (2011).

17. K. Li, X. Zhong, S. Yang, Z. Luo, K. Li, Y. Liu, S. Cai, H. Gu, S. Lu, H. Zhang, Y. Wei, J. Zhuang, Y. Zhuo, Z. Fan, J. Ge. Acta Biomaterialia 54, 117-127 (2017).

18. L. Binan, C. Tendey, G. De Crescenzo, R. El Ayoubi, A. Ajji, M. Jolicoeur. Biomaterials 35, 664- 674 (2014).

19. W. Li, Y. Guo, H. Wang, D. Shi, C. Liang, Z. Ye, F. Qing, J. Gong. Journal of Materials Science: $\quad$ Materials in Medicine 19, 847-854 (2008).

20. K. Zhang, H. Zheng, S. Liang, C. Gao. Acta Biomaterialia 37, 131-142 (2016).

21. J. M. Zuidema, G. P. Desmond, C. J. Rivet, K. R. Kearns, D. M. Thompson, R. J. Gilbert. Biomaterials 46, 82-94 (2015).

22. J. Xie, S. M. Willerth, X. Li, M. R. Macewan, A. Rader, S. E. Sakiyama-Elbert, Y. Xia. Biomaterials 30, 354-362 (2009).

23. J. M. Corey, D. Y. Lin, K. B. Mycek, Q. Chen, S. Samuel, E. L. Feldman, D. C. Martin. Journal of Biomedical Materials Research Part A 83A, 636-645 (2007).

24. L. A. Smith Callahan, S. Xie, I. A. Barker, J. Zheng, D. H. Reneker, A. P. Dove, M. L. Becker. Biomaterials 34, 9089-9095 (2013).

25. S. Panseri, C. Cunha, J. Lowery, U. Del Carro, F. Taraballi, S. Amadio, A. Vescovi, F. Gelain. BMC Biotechnology 8, 39-39 (2008).

26. K. M. Kennedy, A. Bhaw-Luximon, D. Jhurry. Acta Biomaterialia 50, 41-55 (2017).

27. G. T. Christopherson, H. Song, H.-Q. Mao. Biomaterials 30, 556-564 (2009).

28. V. Cirillo, B. A. Clements, V. Guarino, J. Bushman, J. Kohn, L. Ambrosio. Biomaterials 35, 8970-8982 (2014).

29. H. Liu, H. Peng, Y. Wu, C. Zhang, Y. Cai, G. Xu, Q. Li, X. Chen, J. Ji, Y. Zhang, H. W. OuYang. Biomaterials 34, 4404-4417 (2013).

30. C. Li, C. Vepari, H.-J. Jin, H. J. Kim, D. L. Kaplan. Biomaterials 27, 3115-3124 (2006).

31. H. Chen, M. Gigli, C. Gualandi, R. Truckenmüller, C. van Blitterswijk, N. Lotti, A. Munari, M. L. Focarete, L. Moroni. Biomaterials 76, 261-272 (2016).

32. Q. Yao, J. G. L. Cosme, T. Xu, J. M. Miszuk, P. H. S. Picciani, H. Fong, H. Sun. Biomaterials 115, 115-127 (2017).

33. S. Liu, M. Qin, C. Hu, F. Wu, W. Cui, T. Jin, C. Fan. Biomaterials 34, 4690-4701 (2013).

34. Y. J. Lee, J.-H. Lee, H.-J. Cho, H. K. Kim, T. R. Yoon, H. Shin. Biomaterials 34, 5059-5069 (2013).

35. Z. Man, L. Yin, Z. Shao, X. Zhang, X. Hu, J. Zhu, L. Dai, H. Huang, L. Yuan, C. Zhou, H. Chen, Y. Ao. Biomaterials 35, 5250-5260 (2014).

36. Y. Xu, S. Dong, Q. Zhou, X. Mo, L. Song, T. Hou, J. Wu, S. Li, Y. Li, P. Li, Y. Gan, J. Xu. Biomaterials 35, 2760-2772 (2014).

37. M. Deng, S. G. Kumbar, L. S. Nair, A. L. Weikel, H. R. Allcock, C. T. Laurencin. Advanced Functional Materials 21, 2641-2651 (2011).

38. X. Xin, M. Hussain, J. J. Mao. Biomaterials 28, 316-325 (2007).

39. H. Yoshimoto, Y. M. Shin, H. Terai, J. P. Vacanti. Biomaterials 24, 2077-2082 (2003).

40. J. Ye, X. Shi, X. Chen, J. Xie, C. Wang, K. Yao, C. Gao, Z. Gou. Journal of Materials Chemistry $B \quad$ 2, 4226-4236 (2014).

41. P. Deshpande, C. Ramachandran, F. Sefat, I. Mariappan, C. Johnson, R. McKean, M. Hannah, V. S. Sangwan, F. Claeyssens, A. J. Ryan, S. MacNeil. Biomaterials 34, 5088-5106 (2013).

42. K. P. Alena Zajicova, Anna Lencova, Magdalena Krulova,, S. K. Eliska Svobodova, Eva Sykova, Martin Pradny, Jiri Michalek,, M. M. Jana Svobodova, Vladimir Holan. Cell Transplantation 19,1281-1290(2010).

43. J. Cejkova, P. Trosan, C. Cejka, A. Lencova, A. Zajicova, E. Javorkova, S. Kubinova, E. Sykova, $\quad$ V. Holan. Experimental Eye Research 116, 312-323 (2013).

44. B. A. Tucker, S. M. Redenti, C. Jiang, J. S. Swift, H. J. Klassen, M. E. Smith, G. E. Wnek, M. J. Young. Biomaterials 31, 9-19 (2010).

45. M. W. Curtis, B. Russell. Journal of Cardiovascular Nursing 24, 87-92 (2009).

46. C. J. Teng, J. Luo, R. C. J. Chiu, D. Shum-Tim. The Journal of Thoracic and Cardiovascular Surgery 132, 628-632 (2006). 
47. S. E. Senyo, Y. E. Koshman, B. Russell. FEBS Letters 581, $4241-4247$ (2007).

48. T. Dvir, B. P. Timko, M. D. Brigham, S. R. Naik, S. S. Karajanagi, O. Levy, H. Jin, K. K. Parker, R. $\quad$ Langer, D. S. Kohane. Nat Nano 6, 720-725 (2011).

49. S. Sridhar, J. R. Venugopal, R. Sridhar, S. Ramakrishna. Colloids and Surfaces B: Biointerfaces 134, 346-354 (2015).

50. Y. Chen, D. Zeng, L. Ding, X.-L. Li, X.-T. Liu, W.-J. Li, T. Wei, S. Yan, J.-H. Xie, L. Wei, Q.-S. Zheng. BMC Cell Biology 16, 22 (2015).

51. P. Joanne, M. Kitsara, S.-E. Boitard, H. Naemetalla, V. Vanneaux, M. Pernot, J. Larghero, P. Forest, Y. Chen, P. Menasché, O. Agbulut. Biomaterials 80, 157-168 (2016).

52. L. Kan, P. Thayer, H. Fan, B. Ledford, M. Chen, A. Goldstein, G. Cao, J.-Q. He. Experimental Cell Research 347, 143-152 (2016).

53. J. Guan, F. Wang, Z. Li, J. Chen, X. Guo, J. Liao, N. I. Moldovan. Biomaterials 32, 55685580 (2011).

54. H.-J. Chung, J.-T. Kim, H.-J. Kim, H.-W. Kyung, P. Katila, J.-H. Lee, T.-H. Yang, Y.-I. Yang, S.-J. $\quad$ Lee. Journal of Controlled Release 205, 218-230 (2015).

55. B.-J. Kang, H. Kim, S. K. Lee, J. Kim, Y. Shen, S. Jung, K.-S. Kang, S. G. Im, S. Y. Lee, M. Choi, N. $\quad$ S. Hwang, J.-Y. Cho. Acta Biomaterialia 10, 3007-3017 (2014).

56. D. Kai, Q.-L. Wang, H.-J. Wang, M. P. Prabhakaran, Y. Zhang, Y.-Z. Tan, S. Ramakrishna. Acta Biomaterialia 10, 2727-2738 (2014).

57. Y. Liu, Y. Xu, Z. Wang, D. Wen, W. Zhang, S. Schmull, H. Li, Y. Chen, S. Xue. American Journal of Translational Research 8, 1678-1694 (2016).

58. Q. Liu, S. Tian, C. Zhao, X. Chen, I. Lei, Z. Wang, P. X. Ma. Acta Biomaterialia 26, 105-114 (2015).

59. Z. X. Meng, W. Zheng, L. Li, Y. F. Zheng. Materials Chemistry and Physics 125, 606-611 (2011).

60. F. A. Paskiabi, S. Bonakdar, M. A. Shokrgozar, M. Imani, Z. Jahanshiri, M. ShamsGhahfarokhi, M. Razzaghi-Abyaneh. Materials Science and Engineering: C 73, 130-136 (2017).

61. H. Li, M. Wang, G. R. Williams, J. Wu, X. Sun, Y. Lv, L.-M. Zhu. RSC Advances 6, 5026750277 (2016).

62. F. Zheng, S. Wang, S. Wen, M. Shen, M. Zhu, X. Shi. Biomaterials 34, 1402-1412 (2013).

63. L. Tian, M. P. Prabhakaran, X. Ding, D. Kai, S. Ramakrishna. Journal of Materials Science 47, 3272-3281 (2012).

64. H. Zhang, J. Liang, Y. Ding, P. Li. Materials Letters 181, 119-122 (2016).

65. H. Xu, H. Li, J. Chang. Journal of Materials Chemistry B 1, 4182-4188 (2013).

66. S. Nagarajan, L. Soussan, M. Bechelany, C. Teyssier, V. Cavailles, C. Pochat-Bohatier, P. Miele, N. Kalkura, J.-M. Janot, S. Balme. Journal of Materials Chemistry B 4, 1134-1141 (2016).

67. J. Hu, M. P. Prabhakaran, L. Tian, X. Ding, S. Ramakrishna. RSC Advances 5, 100256100267 (2015).

68. Qi, P. Hu, J. Xu, Wang. Biomacromolecules 7, 2327-2330 (2006). 